Article

\title{
Viability of Using High Amounts of Steel Slag Aggregates to Improve the Circularity and Performance of Asphalt Mixtures
}

\author{
Caroline Moura $^{1}\left(\right.$, Lucas Nascimento $^{2}\left(\mathbb{D}\right.$, Carlos Loureiro $^{1}\left(\right.$, Mafalda Rodrigues $^{3}$, Joel Oliveira ${ }^{1}(\mathbb{D}$ \\ and Hugo Silva $1, *(\mathbb{B}$
}

1 ISISE-Institute for Sustainability and Innovation in Structural Engineering, Department of Civil Engineering, University of Minho, 4800-058 Guimaraes, Portugal; id8972@alunos.uminho.pt (C.M.); id9629@alunos.uminho.pt (C.L.); joliveira@civil.uminho.pt (J.O.)

2 CVR-Centre for Waste Valorisation, 4800-042 Guimaraes, Portugal; Inascimento@cvresiduos.pt

3 DST-Domingos da Silva Teixeira, 4700-727 Braga, Portugal; Mafalda.Rodrigues@dstsgps.com

* Correspondence: hugo@civil.uminho.pt; Tel.: +351-253-510200

check for

updates

Citation: Moura, C.; Nascimento, L.; Loureiro, C.; Rodrigues, M.; Oliveira, J.; Silva, H. Viability of Using High Amounts of Steel Slag Aggregates to Improve the Circularity and Performance of Asphalt Mixtures. Appl. Sci. 2022, 12, 490. https:// doi.org/10.3390/app12010490

Academic Editors: Luís Picado Santos and Arminda Almeida

Received: 30 November 2021 Accepted: 29 December 2021 Published: 4 January 2022

Publisher's Note: MDPI stays neutral with regard to jurisdictional claims in published maps and institutional affiliations.

Copyright: (C) 2022 by the authors. Licensee MDPI, Basel, Switzerland. This article is an open access article distributed under the terms and conditions of the Creative Commons Attribution (CC BY) license (https:// creativecommons.org/licenses/by/ $4.0 /)$.

\begin{abstract}
Steel slag is a byproduct generated as waste during the steelmaking process and can be considered a cost-effective and environmentally acceptable alternative to replace natural aggregates. Using steel slag aggregates (SSA) to produce asphalt mixtures promotes sustainability and circular economy principles by using an industrial byproduct as a raw material. Thus, this work mainly aims to design more sustainable asphalt mixtures with high amounts of SSA that fit the circular economy expectations. This work developed two asphalt mixtures with SSA for surface (AC 14 surf) and binder/base (AC 20 bin/base) courses. Initially, the excellent wearing and polishing resistance of SSA and their good affinity with bitumen demonstrated the potential of this byproduct to be used in asphalt mixtures. Then, when analyzing the influence of using two different SSA incorporation rates $(50 \%$ and a percentage close to $100 \%$ ) in both asphalt mixtures, it was concluded that the use of SSA should be limited to $75 \%$ to avoid excessive air void contents and durability problems. The importance of considering the different particle densities of SSA and natural aggregates was highlighted during the mix design by defining a relationship between an effective and equivalent binder content. Finally, the mechanical performance of AC 14 and AC 20 with 75\% SSA incorporation was compared to identical conventional mixtures produced with natural granite aggregates. The results obtained showed that the asphalt mixtures with $75 \%$ SSA have some workability problems due to the rough and porous surface of SSA. However, they present an excellent water sensitivity and permanent deformation resistance, surpassing the performance of the conventional asphalt mixtures.
\end{abstract}

Keywords: steel slag aggregates (SSA); mix design; asphalt pavements; mechanical performance; circular economy

\section{Introduction}

Circular economy (CE) is a concept promoted by the European Union and several governments individually, which can be defined as an economic model based on the natural cycle, aimed at efficiently using resources through waste minimization, long-term value retention, and reduction of primary resources use [1,2].

According to Mantalovas and Di Mino [3], the road engineering industry moves towards more circular approaches. Some standard practices that various stakeholders, companies, asphalt contractors, and agencies are implementing, in line with the circular economy principles, include recycling reclaimed asphalt, extending the service life of their assets (preventive maintenance), and using wastes in asphalt pavements [4].

The road engineering industry's transition to a circular business approach requires managing the resources, energy, and waste more efficiently and sustainably [5]. According to Plati [6], the pavement's sustainability is highly based on the proper selection of materials. 
Thus, the choice of eco-friendly and low-cost materials is part of sustainability principles in pavements while considering social impacts.

Woszuk et al. [7] state that cleaner production in asphalt mixtures aims to completely or partially replace traditional aggregates and fillers with waste materials or their use as additives modifying the binder's composition. The principal constituents of a typical asphalt mixture are the aggregates, and thus, the utilization of industrial waste and byproduct materials in pavement applications as an alternative for natural aggregates contributes to environmental sustainability $[8,9]$. Adjusting asphalt mixtures production with waste materials can also limit the enormous volume of wastes produced from various sources. Furthermore, this solution reduces the consumption of newly mined materials, minimizing the carbon footprint and pavement industry impact on the environment [10].

Although different kinds of recycled materials can be used as aggregates in road construction, it is crucial to know their properties to ensure they meet the same quality standards as natural aggregates to satisfy the same performance standards [11,12].

This work also aims to study the possibility of using steel slag aggregates (SSA) as a substitute for more than $50 \%$ of the natural aggregate in bituminous paving mixes, thus improving the sustainability of the road paving industry. Considering that SSA's mechanical properties may be similar to those of natural aggregates and that this waste is produced in significant quantities, its incorporation in pavements would reduce the volume of this material deposited in landfills, promoting a circular economy.

The steel industry, particularly the steel producer, generates significant amounts of wastes, including slag, commonly known as "steel slag". According to Abd Alhay and Jassim [13], steel slag is a waste material produced during the steelmaking process as a byproduct. Steel slag is commonly categorized according to the furnace used for the refinery process, including basic-oxygen furnace (BOF), blast furnace (BF), and electric-arc furnace (EAF). Among these categories, EAF steel slag (used in this work) is the most common type used in road construction $[9,14]$.

In the last decades, the steel industry in Europe has transitioned towards the electric arc furnace steelmaking technology, being used for approximately $30 \%$ of European steel production [15]. In Portugal, there are two steelworks, one located in Seixal (SN Seixal), and the other in Maia (SN Maia), which belong to Siderurgia Nacional (SN) Empresa de Produtos Longos, SA. Both are equipped with an electric arc furnace, in which the primary raw material used in the melting phase is ferrous scrap [16]. Electric-arc furnaces (minimills) use high-power electric arcs instead of gaseous fuels to produce the heat necessary to melt recycled steel scrap and convert it into high-quality steel. The electric-arc furnace steelmaking process is not dependent on the production from a blast furnace since the main feed is steel scrap with some pig iron [17].

EAF steel slag can substitute aggregates in asphalt mixtures, being considered one of the most promising materials for that purpose. It is a granular material with a high micro-porosity, very high density, around $3.5 \mathrm{Mg} / \mathrm{m}^{3}$, an angular shape, and excellent wear resistance. This slag has excellent properties for use in asphalt mixes, being especially suitable for surface courses where skid resistance and durability are critical functional requirements and for producing asphalt mixes subjected to heavy traffic $[15,18,19]$. Some previous research has shown that using this material improves the mechanical properties of the asphalt mixtures, such as durability, workability, stiffness, permeability, stability, resistance to fatigue, and permanent deformation [20-25].

However, there is no standard for the proportioning of steel slag with natural aggregate, but, if partially replaced at about $20 \%$ to $100 \%$, it provides satisfactory results [23]. Therefore, as this work aims to maximize the incorporation of SSA in asphalt mixtures, two phases are planned to evaluate the incorporation of different percentages of SSA. In the first phase, asphalt mixtures are produced with variable incorporation rates, from a less ambitious value (50\%) up to the maximum possible value (closer to $100 \%$ ) that fulfils the grading specifications. This preliminary phase showed the evolution of the asphalt mixtures composition and performance for different incorporation rates. In a second 
phase, optimized asphalt mixtures are designed using 75\% SSA for further performance evaluation, showing the potential of this alternative aggregate for paving works.

\section{Materials and Methods}

\subsection{Materials}

The materials used in this project were SSA, resulting from the processing of steel slag (Figure 1a), natural granitic aggregates (Figure 1b), limestone filler, and 35/50 pen bitumen.

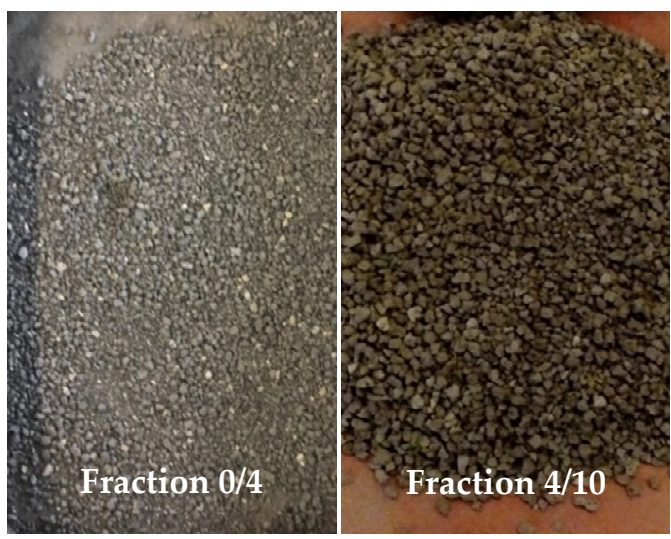

(a)

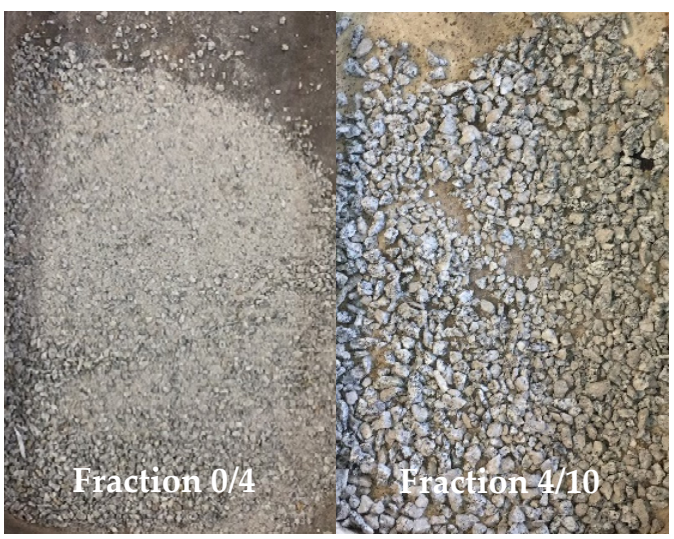

(b)

Figure 1. Materials used in this work: (a) steel slag aggregates (SSA) and (b) natural aggregates (NA).

\subsection{Aggregate Characterization}

The density of the aggregates was determined following the EN 1097-6 standard. This volumetric characteristic of the aggregates is relevant to design asphalt mixtures and can help to understand their future behavior. The use of a non-conventional material (SSA) with high density makes the evaluation of this characteristic even more critical.

The water absorption test should be used as a screening test for aggregates subjected to high humidity environments (EN 1097-6). The water absorption limit for base and binder courses is $2 \%$ and $1 \%$ for surface layers [26].

The micro-Deval test allows measuring the wear resistance of an aggregate to assess the feasibility of its application in asphalt mixtures. The test was conducted following the EN 1097-1 standard, using a sample of the 10/14 SSA fraction. After concluding the micro-Deval test, the difference between the initial mass of the sample and the final mass retained in the \#1.6 mm sieve was used to calculate the frictional wear of the SSA aggregates, known as the micro-Deval coefficient.

The resistance of coarse aggregates to polishing, when used in surface course asphalt mixtures, is evaluated through the accelerated polishing test (EN 1097-8). As a result of this test, the polished stone value (PSV) was determined. For aggregates to be used in pavement surface courses, their PSV should be greater than 50 [26].

The binder-aggregate affinity test was carried out to determine if the asphalt binder and the aggregates present an adequate bonding. According to the EN 12697-11 standard, two operators conduct the test based on a visual record of the level of aggregates surface covered with bitumen at specified testing periods (up to $24 \mathrm{~h}$ ).

The particle size distribution of the different aggregate fractions, both for the SSA $(0 / 4,4 / 10,10 / 14$ and $0 / 20)$ and the natural aggregates $(0 / 4,4 / 10,10 / 14$ and $14 / 20)$, was determined using the EN 933-1 standard to assist the design of asphalt mixtures in complying with the specifications [26].

\subsection{Bitumen Characterization}

The bitumen was characterized through penetration at $25^{\circ} \mathrm{C}$ (EN 1426) and softening point tests, the latter using the ring and ball method (EN 1427). 


\subsection{Preliminary Study to Evaluate the Amount of SSA to Incorporate in the Asphalt Mixtures}

This work aims to maximize the incorporation of SSA in two types of asphalt mixtures for surface and binder/base courses. Ideally, those mixtures should have nearly $100 \%$ SSA aggregates while fulfilling their grading envelope. However, as the behavior associated with the use of SSA was unknown, asphalt mixtures with a less ambitious amount of incorporation $(50 \%)$ were also produced, which would allow understanding the influence of different incorporation rates on the performance of the asphalt mixtures.

In this preliminary study, all mixtures were produced with $5 \%$ bitumen (commonly used in asphalt mixtures) to reduce the number of independent variables under analysis.

\subsubsection{Particle Size Adjustment of Asphalt Mixtures for Different SSA Incorporation Rates}

The asphalt mixtures to be studied were initially designed based on the various aggregate fractions' density and particle size distribution, adjusting the final grading curves to the specified grading envelopes [26]. Two surface course mixtures (AC 14 surf 35/50 BB) and two binder/base course mixtures (AC 20 bin/base 35/50 MB) were studied, taking into account the different SSA incorporation rates ( $50 \%$ or nearly $100 \%$ ). Due to the low presence of fine material in the SSA, the maximum rates of SSA incorporation were $80 \%$ in the surface course mixture (AC 14) and 95\% in the binder/base course mixture (AC 20).

\subsubsection{Production of Mixtures and Compaction of Marshall Specimens}

After completing the particle size adjustment, the asphalt mixtures were produced with an equivalent binder content of $5.0 \%$, usually applied in asphalt mixtures with natural aggregates (NA). However, the effective binder content decreases as the amount of SSA used in the mixture increases, due to its high density, according to Equation (1):

$$
\mathrm{BC}_{\mathrm{Eff}}=\mathrm{BC}_{\mathrm{Equi}} \times \mathrm{APD}_{\mathrm{NA}} / \mathrm{APD}_{\mathrm{Agg} \text { Mix }}
$$

where $\mathrm{BC}_{\mathrm{Eff}}$ is the effective binder content used in the asphalt mixture, $\mathrm{BC}_{\mathrm{Equi}}$ is the equivalent binder content of a similar asphalt mixture produced with NA, APD $\mathrm{NA}_{\mathrm{N}}$ is the apparent particle density of the NA, and $\mathrm{APD}_{\mathrm{Agg} \text { Mix }}$ is the apparent particle density of the SSA and NA blend used in the mixture.

Thus, the effective binder content used to produce each mixture was as follows:

- AC 14 surf $35 / 50$ with 50\% SSA using $4.5 \%$ bitumen;

- AC 14 surf $35 / 50$ with $80 \%$ SSA using $4.2 \%$ bitumen;

- AC 20 surf 35/50 with 50\% SSA using $4.5 \%$ bitumen;

- AC 20 surf $35 / 50$ with $95 \%$ SSA using $4.1 \%$ bitumen.

The mixing temperature for all mixtures was $165^{\circ} \mathrm{C}$, based on the EN 12697-35 standard, for a 35/50 bitumen. After producing the asphalt mixtures, Marshall specimens were compacted with 75 blows per face, according to the EN $12697-30$ standard, at $135-140{ }^{\circ} \mathrm{C}$. At this stage of the work, six samples of each mixture were used to determine the sensitivity to water after assessing their air voids content.

\subsubsection{Volumetric Properties of the Asphalt Mixtures}

The specimens' bulk density was obtained using method B of standard EN 12697-6. Then, each mixture's maximum density (MD) was assessed using a pycnometer, as established in the EN 12697-5 standard. Those values were used to calculate the air void content (Va). The Va limits specified in Portugal [26] are essential during the mix design phase.

\subsubsection{Evaluation of the Water Sensitivity of the Asphalt Mixtures}

This work used the water sensitivity test (EN 12697-12) as the preliminary performance control test. It was necessary to store three specimens at room temperature, without conditioning in water, while a second group was conditioned in water for three days at $40{ }^{\circ} \mathrm{C}$. Finally, all the samples were tested by indirect tension at $15^{\circ} \mathrm{C}$ (EN 12697-23). 
The test results are the average indirect tensile strength of the conditioned in water $\left(\mathrm{ITS}_{\mathrm{W}}\right)$ or dry $\left(\mathrm{ITS}_{\mathrm{d}}\right)$ specimens. The indirect tensile strength ratio (ITSR) is the ratio between ITS $_{\mathrm{w}}$ and ITS $\mathrm{d}_{\mathrm{d}}$ and is the main parameter used to evaluate water sensitivity. According to current practice, the asphalt mixtures should have ITSR values higher than $70 \%$ or ideally $80 \%$ to assure adequate performance $[26,27]$.

\subsection{Mix Design of the Resulting Asphalt Mixtures with SSA after the Preliminary Study}

The preliminary study results show suitable particle size adjustments and properties for AC 14 and AC 20 mixtures incorporating 50\% SSA. However, adjusting the grading curves for the asphalt mixtures with $80 \%$ SSA (AC 14) or 95\% SSA (AC 20) was very challenging, resulting in air void contents above the specification limits. Thus, an intermediate value of $75 \%$ was defined for the SSA incorporation rate for the next phase of the study, maximizing the SSA incorporation rate (to improve the circularity) without compromising the asphalt mixtures' composition and performance. Therefore, each aggregate fraction needed to adjust the final grading curves of these mixtures was re-evaluated.

Then, the Marshall mix design method (EN 13108-1) was used to determine the optimum binder content (OBC) for the asphalt mixtures with 75\% SSA. This study is even more relevant due to the greater porosimetry and water absorption of the SSA.

The mix design study for AC 14 and AC 20 mixtures used different batches produced with five effective binder contents $(3.4 \%, 3.8 \%, 4.3 \%, 4.7 \%$, and $5.1 \%$, which correspond to the previously explained equivalent values of $4.0 \%, 4.5 \%, 5.0 \%, 5.5 \%$, and $6.0 \%$, respectively). The mixing and compaction conditions and the volumetric characterization were identical to those mentioned in Section 2.4. The bulk density, air void content (Va), and voids in mineral aggregates (VMA) are essential properties to define the OBC. The Marshall stability and the corresponding deformation of each specimen were obtained according to EN 12697-34.

\subsection{Evaluation of the Mechanical Performance of the Selected Asphalt Mixtures}

The mix design of AC 14 and AC 20 mixtures with 75\% SSA was followed by their mechanical performance evaluation and comparison to conventional asphalt mixtures of a similar composition produced with natural aggregates.

\subsubsection{Particle Size Adjustment of Mixtures with Natural Aggregates and Production of} Testing Specimens

Each fraction of natural aggregates (NA) used to produce the conventional asphalt mixtures was calculated to fulfil the specified grading envelope. The particle size adjustment was set to overlap, as much as possible, the grading curve used in the asphalt mixtures with $75 \%$ SSA. Furthermore, an equivalent binder content was used for these conventional mixtures taking into account the density differential previously explained.

The mixing conditions and the volumetric characterization of the specimens were the same used in Sections 2.4 and 2.5. Regarding the compaction of the test specimens, cylindrical specimens for water sensitivity tests were produced with the Marshall impact compactor, and slabs with $30 \times 30 \times 4 \mathrm{~cm}$ were compacted in a roller compactor (EN 12697-33) to be tested for permanent deformation (wheel tracking test).

Examples of a conventional mixture (AC 20) with natural granitic aggregates and the corresponding asphalt mixture with $75 \%$ SSA can be observed in Figure 2. The images were taken after production, compaction, and sawing of the specimens. 

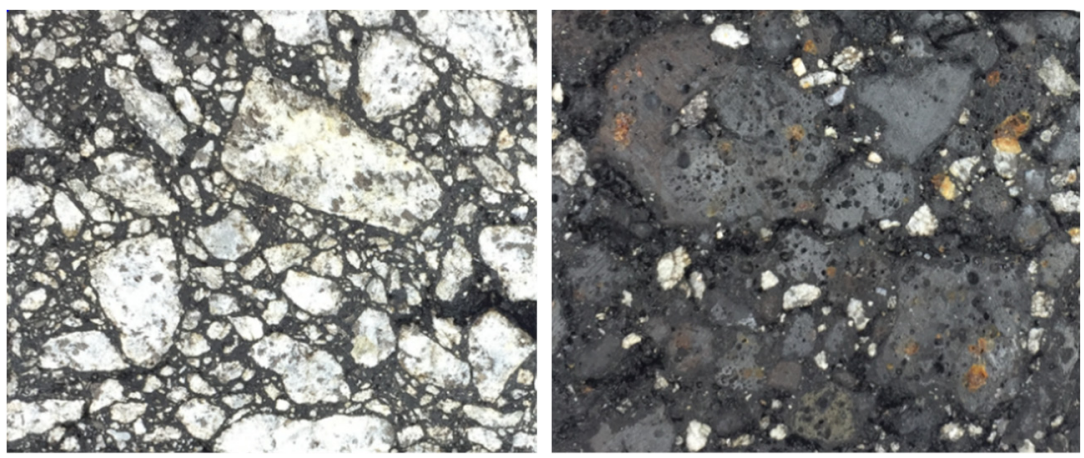

Figure 2. AC 20 bin/base mixture with natural granitic aggregates (left) and equivalent asphalt mixture with $75 \%$ SSA (right).

\subsubsection{Water Sensitivity of the Selected Asphalt Mixtures}

The water sensitivity test was already described during the preliminary study phase (Section 2.4) as a performance control test for the initial asphalt mixtures with SSA. This property must be assessed again to compare and validate the performance of the asphalt mixtures with $75 \%$ SSA against the equivalent conventional asphalt mixtures with NA.

\subsubsection{Permanent Deformation Resistance of the Selected Asphalt Mixtures}

The wheel tracking test (WTT) was used to evaluate the resistance to permanent deformation according to EN 12697-22. It consists of repeatedly passing a wheel over the asphalt mixture at a high operating temperature $\left(60^{\circ} \mathrm{C}\right)$ while measuring the evolution of the wheel rut depth with the number of cycles, up to 10,000.

As for the results obtained in this test, the main one is the wheel tracking slope $\left(\mathrm{WTS}_{\text {AIR }}\right)$, which indicates the increase in deformation per thousand cycles between the 5000th and the 10,000th cycles. The other parameters obtained in this test are the mean proportional rut depth $\left(\mathrm{PRD}_{\mathrm{AIR}}\right)$ and the final rut depth $\left(\mathrm{RD}_{\mathrm{AIR}}\right)$.

\section{Results and Discussion}

\subsection{Aggregates Characterization}

\subsubsection{Particle Density and Water Absorption}

Table 1 presents the results of the particle density and water absorption of the SSA and natural aggregates (NA), using the 10/14 fraction.

Table 1. Result of SSA and NA particle density and water absorption.

\begin{tabular}{cccc}
\hline Parameter & Unity & SSA & NA \\
\hline Apparent particle density & $\left(\mathrm{Mg} / \mathrm{m}^{3}\right)$ & 3.40 & 2.69 \\
Particle density on a saturated and surface-dried basis & $\left(\mathrm{Mg} / \mathrm{m}^{3}\right)$ & 3.29 & 2.64 \\
Pre-dried particle density & $\left(\mathrm{Mg} / \mathrm{m}^{3}\right)$ & 3.35 & 2.66 \\
Water absorption & $(\%)$ & 1.3 & 0.7 \\
\hline
\end{tabular}

This test demonstrates that the particle density of SSA is approximately $25 \%$ higher than that of the natural granitic aggregates, which may have a significant effect on the mix design of asphalt mixtures with SSA. Moreover, the asphalt mixture weight increases for the same area or volume of road paving application, impacting transportation costs. The water absorption of SSA is also higher than that of the natural granite aggregates due to its increased porosity, suggesting an increased amount of bitumen absorbed and the need for higher binder contents during asphalt mixture production. 


\subsubsection{Resistance to Wear through the Micro-Deval Coefficient}

The micro-Deval test was performed with aggregates from the 10/14 fraction of SSA, resulting in a micro-Deval coefficient (MDE) of 9.9\%. Previous studies $[16,28]$ also obtained SSA MDE values lower than 11\%. The usual MDE values for granitic aggregates are slightly higher (around 15\%), but do not exceed 20\% [29], showing that SSA has high wear resistance. Thus, no limitations were identified for replacing natural aggregates with SSA in asphalt mixtures.

\subsubsection{Resistance of Aggregates to Polishing}

The test used to evaluate the resistance of aggregates to polishing was carried out on three aggregate groups of different origins: SSA, natural granitic, and control aggregates. Figure 3 shows the polishing stone values (PSV) measured in the British pendulum friction tester before and after polishing.

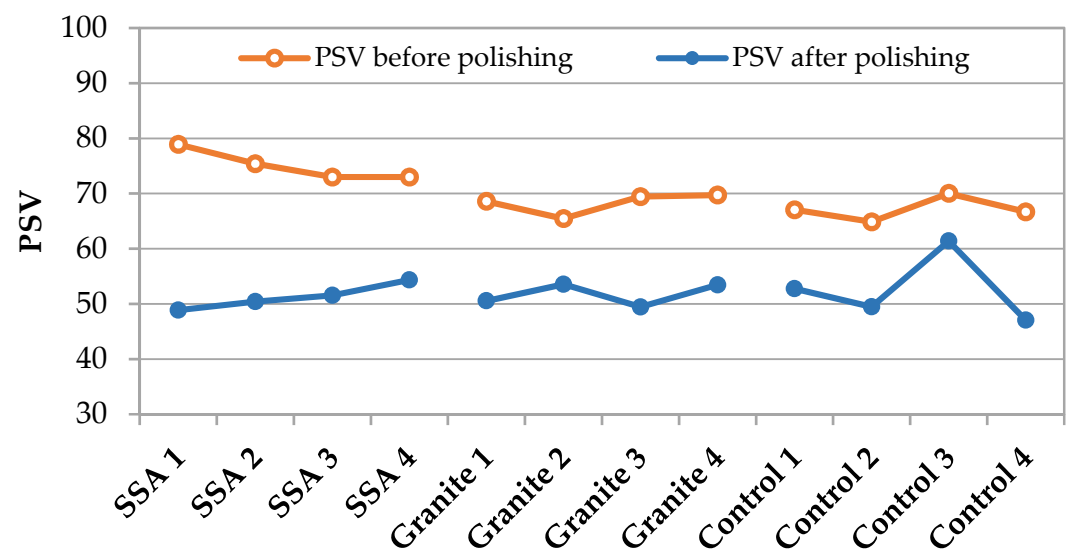

Figure 3. PSV results were obtained before and after the accelerated polishing test.

The accelerated polishing effect on the aggregates during the test is evident by reducing the PSV values. The SSA aggregates presented the highest PSV values before testing. However, the PSV results obtained after polishing the SSA are equivalent to those for the other types of aggregates evaluated. The final result of this test, calculated with the average PSV values after the accelerated polishing procedure, is shown in Table 2. Both the SSA and NA aggregates showed PSV values higher than the standard limit of 50 [26]. Thus, the SSA can be used in asphalt mixtures for road surface courses.

Table 2. Polishing stone values (PSV) of the studied aggregates.

\begin{tabular}{cc}
\hline Aggregate Sample & PSV \\
\hline SSA & 51.1 \\
Natural granite & 51.6 \\
Control aggregate & 52.7 \\
\hline
\end{tabular}

\subsubsection{Affinity between Aggregates and Bitumen}

Table 3 shows the results observed by two operators (Figure 4) for the binder-aggregate affinity for the specified SSA fraction, which is the percentage of aggregate surface that remains covered with bitumen during $(6 \mathrm{~h})$ and after the test $(24 \mathrm{~h})$.

This test is significantly aggressive, given the conditions under which it is carried out, and the results usually obtained for granite aggregates are generally low (i.e., around $10 \%)[30,31]$. However, the affinity of bitumen with SSA (50\% to $65 \%)$ is significantly higher due to its higher porosity and rough surface. Therefore, it can be concluded that SSA can substitute the natural aggregates to improve the asphalt mixture performance. 
Table 3. Determination of affinity between SSA and bitumen.

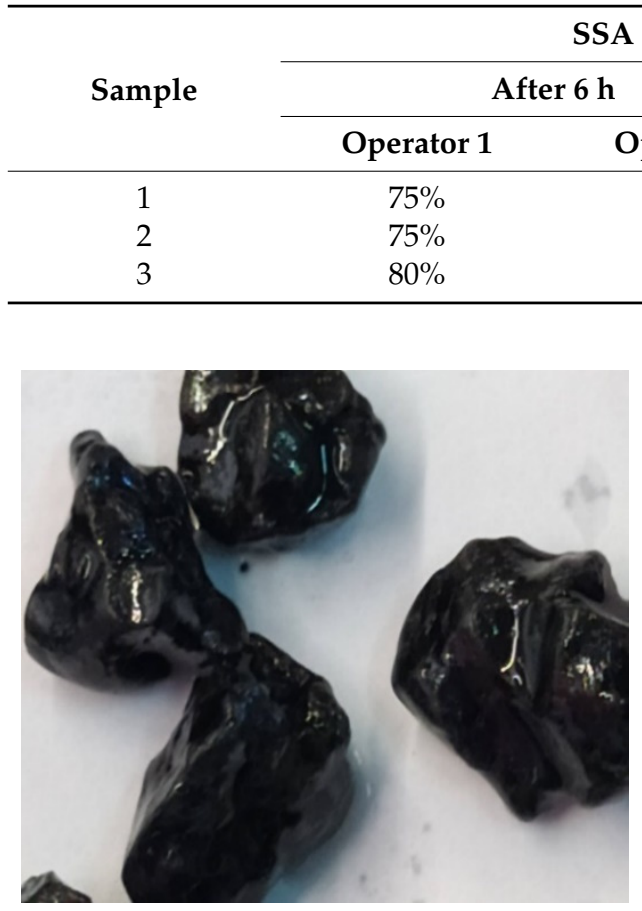

(a)

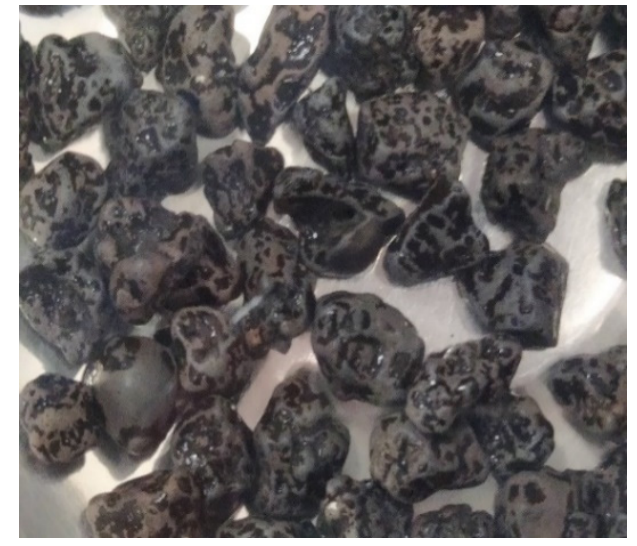

(b)

Figure 4. Examples of SSA aggregates surface covered with bitumen: (a) at the beginning of the affinity test; (b) after $24 \mathrm{~h}$ of exposure to test conditions.

\subsubsection{Particle Size Distribution of the Aggregates}

It is essential to know the particle size distribution of the several fractions of natural aggregates (NA) and SSA to design the asphalt mixtures studied in this work. The results of this test are the grading curves presented in Figure 5 and show that SSA aggregates have fewer fines than natural aggregates, especially in fraction $0 / 4$.

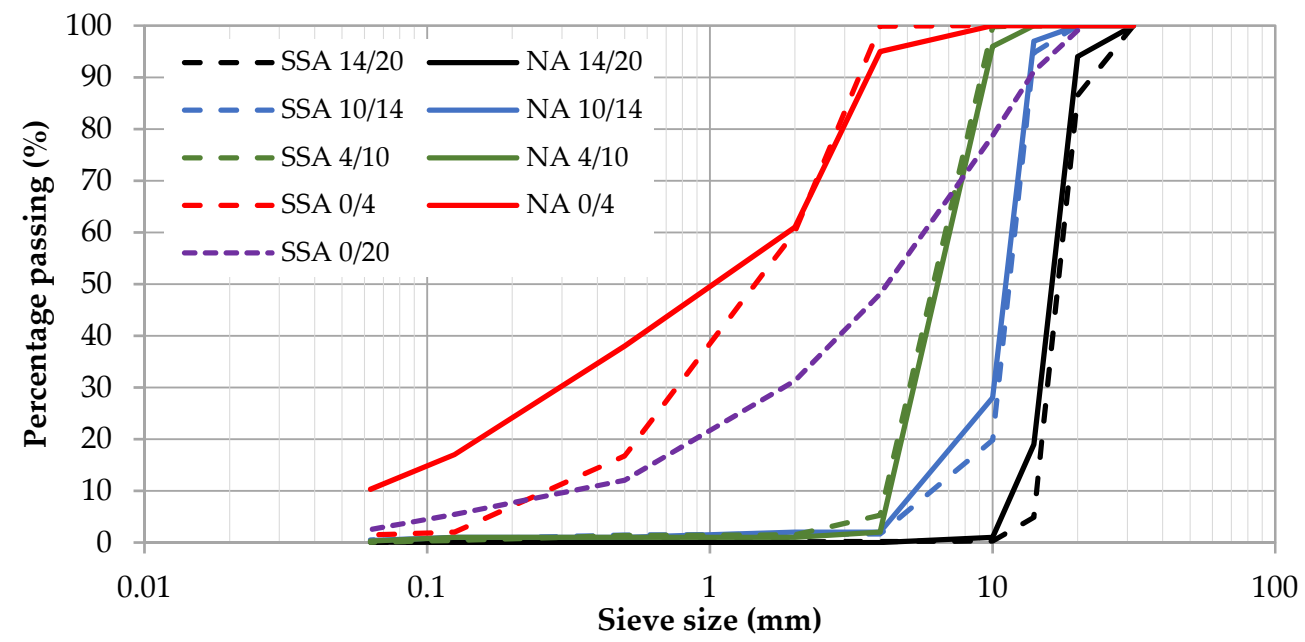

Figure 5. Particle size distribution of the different fractions of SSA and NA.

\subsection{Bitumen Characterisation}

A 35/50 pen bitumen was used in this work because it is the most used in the country. The bitumen has a penetration value of 36.7 tenths of a millimeter and a softening point of $50.2{ }^{\circ} \mathrm{C}$, complying with the established EN 12591 limits for the assigned classification. 


\subsection{Preliminary Study to Evaluate the Amount of SSA to Incorporate in the Asphalt Mixtures}

Considering that SSA is more porous and rougher than granite aggregates, the workability of the corresponding asphalt mixtures might be lower. Thus, two SSA percentages were used in this preliminary study to verify the maximum SSA incorporation rate that can result in asphalt mixtures with adequate volumetric characteristics and durability.

\subsubsection{Particle Size Adjustment of Asphalt Mixtures for Different SSA Incorporation Rates}

The grading curves of two asphalt mixtures were studied in this preliminary phase based on the relevant specifications [26]: one for the surface course, AC 14 surf 35/50 (BB), and the other for binder/base courses, AC 20 bin/base 35/50 (MB). Different amounts of SSA and NA fractions were used, bearing in mind the objective of producing AC 14 mixtures with 50\% and 80\% SSA and AC 20 mixtures with 50\% and 95\% SSA incorporation rates. The maximum SSA incorporation rates ( $80 \%$ and $95 \%$ ) resulted from the grading envelope restrictions of the specifications, stricter for surface courses. Figure 6 shows the particle size adjustments obtained for both mixtures (AC 14 and AC 20), resulting from using the compositions shown in Table 4 . The values indicated in Table 4 were determined based on the aggregates' size, thus considering volumetric proportions. The equivalent mass values used during production were calculated based on the aggregates' density.

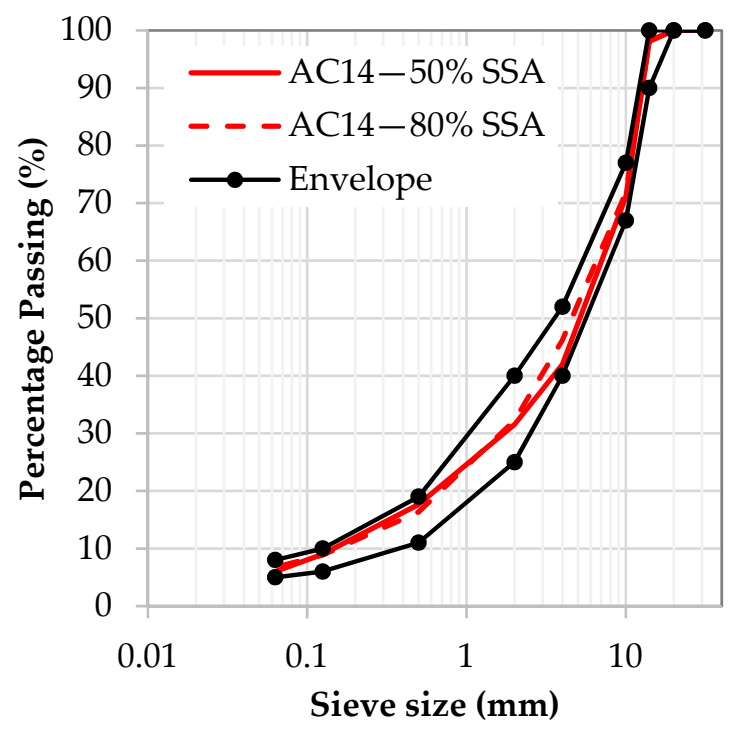

(a)

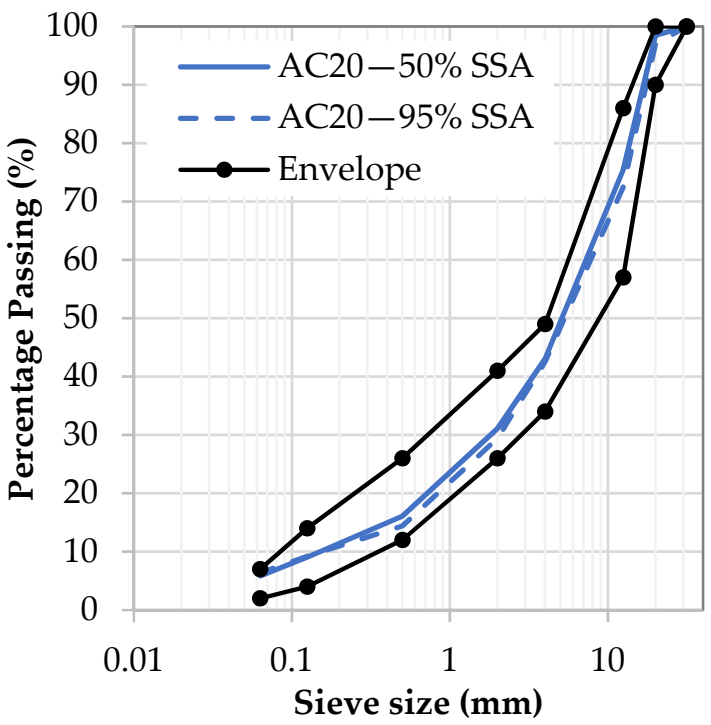

(b)

Figure 6. Grading curve adjustments for the asphalt mixtures with different SSA incorporation rates: (a) AC 14; (b) AC20.

Table 4. Composition of the different asphalt mixtures evaluated in the preliminary study.

\begin{tabular}{|c|c|c|c|c|c|c|c|c|c|c|c|}
\hline \multicolumn{2}{|l|}{ Fraction } & $\begin{array}{l}\text { SSA } \\
0 / 20\end{array}$ & $\begin{array}{c}\text { SSA } \\
14 / 20\end{array}$ & $\begin{array}{c}\text { SSA } \\
10 / 14\end{array}$ & $\begin{array}{l}\text { SSA } \\
4 / 10\end{array}$ & SSA $0 / 4$ & $\begin{array}{c}\text { NA } \\
14 / 20\end{array}$ & $\begin{array}{c}\text { NA } \\
10 / 14\end{array}$ & NA $4 / 10$ & NA $0 / 4$ & Commercial Filler \\
\hline \multirow{2}{*}{ AC 14 Surf 35/50 } & $50 \%$ SSA & - & - & $36 \%$ & $7 \%$ & $7 \%$ & - & - & $16 \%$ & $30 \%$ & $4 \%$ \\
\hline & $80 \%$ SSA & - & - & $35 \%$ & $20 \%$ & $25 \%$ & - & - & - & $14 \%$ & $6 \%$ \\
\hline \multirow{2}{*}{$\begin{array}{c}\text { AC } 20 \text { Bin/Base } \\
35 / 50\end{array}$} & $50 \%$ SSA & $50 \%$ & - & - & - & - & $16 \%$ & $15 \%$ & - & $15 \%$ & $4 \%$ \\
\hline & $95 \%$ SSA & $78 \%$ & $17 \%$ & - & - & - & - & - & - & - & $5 \%$ \\
\hline
\end{tabular}

\subsubsection{Volumetric Characteristics of the Preliminary Asphalt Mixtures}

The volumetric characteristics of the asphalt mixtures were obtained using the maximum density (MD) and the bulk density, which allows the calculation of the air void content (Va) of each specimen. The results of this characterization can be seen in Table 5, which shows the average values of each asphalt mixture. 
Table 5. Volumetric characterization of the mixtures evaluated in the preliminary study.

\begin{tabular}{ccccc}
\hline Mixture & SSA Incorporation & MD $\mathbf{( k g / \mathbf { m } ^ { \mathbf { 3 } } )}$ & Bulk Density $\mathbf{( k g / \mathbf { m } ^ { \mathbf { 3 } } )}$ & Va (\%) \\
\hline \multirow{2}{*}{ AC14 } & $50 \%$ & 2717 & 2609 & $3.9 \%$ \\
& $80 \%$ & 2925 & 2739 & $6.4 \%$ \\
\multirow{2}{*}{ AC20 } & $50 \%$ & 2754 & 2553 & $7.3 \%$ \\
& $95 \%$ & 3077 & 2719 & $11.6 \%$ \\
\hline
\end{tabular}

As shown in Table 5, the higher density of SSA significantly influences the density values obtained for the asphalt mixtures, making it difficult to comply with the maximum air void content limits, particularly when incorporating higher rates of SSA.

\subsubsection{Water Sensitivity of the Preliminary Asphalt Mixtures}

After the volumetric characterization, the specimens produced in this preliminary study were used to evaluate the water sensitivity of the asphalt mixtures with SSA. The average results obtained are presented in Table 6 , including the indirect tensile strength of the dry $\left(\mathrm{ITS}_{\mathrm{d}}\right)$ and water $\left(\mathrm{ITS}_{\mathrm{w}}\right)$ conditioned specimens, as well as the primary indicator of water sensitivity, the indirect tensile strength ratio (ITSR).

Table 6. Water sensitivity test results of the preliminary asphalt mixtures with SSA.

\begin{tabular}{cccc}
\hline \multirow{2}{*}{ Mixture } & \multicolumn{2}{c}{ Indirect Tensile Strength (kPa) } & \multirow{2}{*}{ ITSR (\%) } \\
\cline { 2 - 3 } & ITS $_{\mathbf{d}}$ & ITS $_{\mathbf{w}}$ & \\
\hline AC 14 (50\% SSA) & 3100 & 2776 & 90 \\
AC 14 (80\% SSA) & 3026 & 2865 & 95 \\
AC 20 (50\% SSA) & 2928 & 2247 & 77 \\
AC 20 (95\% SSA) & 2557 & 2445 & 96 \\
\hline
\end{tabular}

The results obtained show that the mixtures with SSA have high ITSR values meeting the 70\% limit mentioned in Section 2.4.4 for adequate performance in road paving. Furthermore, the ITS values of all asphalt mixtures are elevated. Traditionally, the ITSR results of asphalt mixtures are inversely proportional to their air void contents. However, these mixtures with SSA do not follow this trend since the asphalt mixtures with higher SSA incorporation rates have simultaneously higher air void contents and ITSR values. Thus, it is concluded that the asphalt mixtures with high SSA incorporation rates are not very sensitive to the presence of water due to the excellent SSA affinity with bitumen.

In conclusion, asphalt mixtures with very high rates of SSA incorporation will not present water sensitivity problems, but should be avoided due to workability issues since they typically show air void contents above the specification limits.

\subsection{Mix Design Study of Asphalt Mixtures with SSA Resulting from the Preliminary Study}

The preliminary study showed that the particle size adjustment and performance were satisfactory for 50\% SSA incorporation in asphalt mixtures. However, the air void contents are higher than desirable when using $80 \%$ or $95 \%$ SSA. Thus, to maximize the SSA incorporation rate without compromising the composition and performance of the studied mixtures, it was concluded that a 75\% SSA incorporation rate should be used in the Marshall mix design method and performance study of the selected asphalt mixtures.

\subsubsection{Particle Size Adjustment of the Selected Asphalt Mixtures with $75 \%$ SSA}

The Marshall mix design study begins with the grading curve adjustment of each asphalt mixture (AC 14 and AC 20) with 75\% SSA to the corresponding standard envelope after combining different amounts of natural aggregates and SSA (Table 7). The final grading curves adjusted for these mixtures with $75 \%$ SSA are presented below (Figure 7) to compare with curves of equivalent conventional mixtures with natural aggregates. 
Table 7. Composition of the selected asphalt mixtures with $75 \%$ SSA.

\begin{tabular}{ccc}
\hline Fraction & AC 14 Surf 35/50 (BB) & AC 20 Bin/Base 35/50 (MB) \\
\hline SSA 0/20 & - & $62 \%$ \\
SSA 10/14 & $29 \%$ & $13 \%$ \\
SSA 4/10 & $31 \%$ & - \\
SSA 0 /4 & $15 \%$ & - \\
NA 14/20 & - & $6 \%$ \\
NA 0/4 & $20 \%$ & $17 \%$ \\
Commercial filler & $5 \%$ & $2 \%$ \\
\hline
\end{tabular}

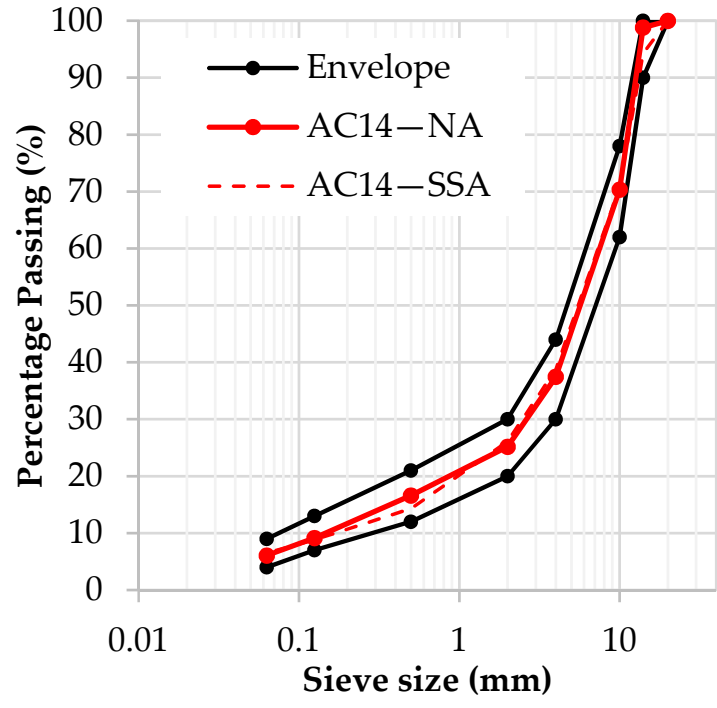

(a)

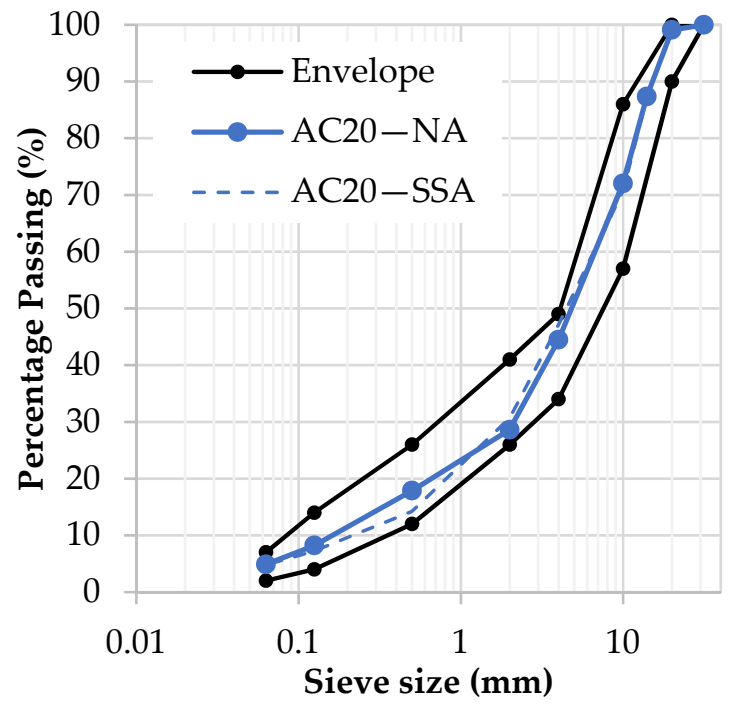

(b)

Figure 7. Grading curve adjustments for the conventional asphalt mixtures with natural aggregates (NA) and the selected asphalt mixture with 75\% SSA: (a) AC 14; (b) AC 20.

The main fraction of natural aggregates added to the mixtures incorporating $75 \%$ SSA was the $0 / 4$ fraction because the SSA does not have enough particles of this size to meet the specified grading envelope. Moreover, these mixtures with SSA also need higher amounts of commercial filler than usual in conventional asphalt mixtures.

\subsubsection{Results of the Marshall Mix Design Method for the Selected Asphalt Mixtures}

The optimum binder contents (OBC) of AC 14 and AC 20 mixtures with 75\% SSA were determined according to the Marshall mix design method. Table 8 presents the average densities (MD and bulk density) and the corresponding values of Va and VMA obtained for each binder content used in the study. After the specimens' volumetric characterization, they were subjected to the Marshall stability test, through which the results of maximum force (stability) and deformation at failure are obtained, as shown in Table 9.

Table 8. Volumetric characteristics of mixtures with 75\% SSA for different binder contents.

\begin{tabular}{ccccccccc}
\hline \multirow{2}{*}{ Equivalent Binder Content } & \multicolumn{2}{c}{ MD $\left(\mathbf{k g} / \mathbf{m}^{\mathbf{3}}\right)$} & \multicolumn{2}{c}{ Bulk Density $\mathbf{( k g / \mathbf { m } ^ { 3 } )}$} & \multicolumn{2}{c}{ Va (\%) } & \multicolumn{2}{c}{ VMA (\%) } \\
\cline { 2 - 9 } & AC 14 & AC 20 & AC 14 & AC 20 & AC 14 & AC 20 & AC 14 & AC 20 \\
\hline $4.0 \%$ & 3013 & 3049 & 2746 & 2617 & 8.9 & 14.2 & 17.9 & 22.8 \\
$4.5 \%$ & 2937 & 3011 & 2747 & 2686 & 6.5 & 10.8 & 16.6 & 20.7 \\
$5.0 \%$ & 2914 & 2962 & 2793 & 2714 & 4.1 & 4.9 & 15.6 & 16.2 \\
$5.5 \%$ & 2873 & 2907 & 2794 & 2699 & 2.7 & 7.5 & 15.3 & 19.6 \\
$6.0 \%$ & 2842 & 2854 & 2833 & 2736 & 0.8 & 4.3 & 14.6 & 17.7 \\
\hline
\end{tabular}


Table 9. Marshall stability and deformation results for selected mixtures with $75 \%$ SSA.

\begin{tabular}{ccccc}
\hline \multirow{2}{*}{$\begin{array}{c}\text { Equivalent } \\
\text { Binder Content }\end{array}$} & \multicolumn{2}{c}{ Marshall Stability (kN) } & \multicolumn{2}{c}{ Deformation at Failure (mm) } \\
\cline { 2 - 5 } & AC 14 & AC 20 & AC 14 & AC 20 \\
\hline $4.0 \%$ & 20.2 & 13.7 & 3.7 & 3.2 \\
$4.5 \%$ & 17.9 & 16.6 & 3.8 & 3.7 \\
$5.0 \%$ & 21.5 & 18.2 & 3.8 & 3.8 \\
$5.5 \%$ & 19.7 & 17.0 & 4.1 & 3.8 \\
$6.0 \%$ & 20.9 & 16.8 & 4.6 & 4.3 \\
\hline
\end{tabular}

The results obtained in the Marshall method were then analyzed to determine the $\mathrm{OBC}$, considering the binder contents resulting in the maximum bulk density and Marshall stability and the mean value of Va specified for each type of mixture.

Based on the analysis of the results of the surface course mixture (AC 14), the OBC is situated at $5.0 \%$. This binder content also results in values of VMA and deformation at failure that meet the specified criteria. A similar result was observed for the AC 20 mixture regarding the optimum binder content parameters. Likewise, the use of $5.0 \%$ bitumen would result in VMA values and deformation at failure that meets the specification limits. Thus, the remainder of this work used a binder content of $5.0 \%$ for both asphalt mixtures (AC 14 and AC 20).

\subsection{Evaluation of the Mechanical Performance of the Selected Asphalt Mixtures}

After finishing the mix design study, the mechanical performance and the relevant volumetric properties of the asphalt mixtures with $75 \%$ SSA were evaluated. Furthermore, conventional asphalt mixtures with NA, with similar compositions, were also produced to compare and confirm the global quality of the new solutions with SSA.

\subsubsection{Particle Size Adjustment of Mixtures with Natural Aggregates}

Initially, the grading curve of the asphalt mixtures with natural aggregates was adjusted (Figure 7) within their standard grading envelope, trying to overlap the equivalent grading curves of the asphalt mixtures with $75 \%$ SSA. The final solutions were obtained by combining the amounts of the NA fractions shown in Table 10. The asphalt mixtures with SSA or NA were defined to have the same binder content, using Equation (1) previously presented (5.0\% for the conventional and $4.3 \%$ when incorporating $75 \%$ SSA).

Table 10. Composition of the conventional asphalt mixtures with natural aggregates.

\begin{tabular}{ccc}
\hline Fraction & AC 14 Surf 35/50 (BB) & AC 20 Bin/Base 35/50 (MB) \\
\hline NA 14/20 & - & $15 \%$ \\
NA 10/14 & $40 \%$ & $17 \%$ \\
NA 4/10 & $22 \%$ & $23 \%$ \\
NA 0/4 & $35 \%$ & $44 \%$ \\
Commercial filler & $3 \%$ & $1 \%$ \\
\hline
\end{tabular}

Figure 7 shows that the conventional mixtures' grading curves could closely overlap the equivalent mixtures' grading curves with $75 \%$ SSA. However, the smaller dimensions $(0.125$ to $2.0 \mathrm{~mm})$ present slight differences, resulting from fewer particles of these dimensions ( $0 / 4$ fraction) in the SSA than those in the natural aggregates.

\subsubsection{Water Sensitivity of the Selected Asphalt Mixtures}

The water sensitivity test was carried out to characterize the two asphalt mixtures with $75 \%$ SSA and the equivalent conventional mixtures. The main results obtained with this test $\left(\mathrm{IST}_{\mathrm{d}}, \mathrm{ITS}_{\mathrm{w}}\right.$ and ITSR), including the average densities and air void contents of the different asphalt mixtures, are shown in Table 11. 
Table 11. Water sensitivity test results for mixtures with 75\% SSA and natural aggregates.

\begin{tabular}{|c|c|c|c|c|c|c|c|}
\hline \multirow{2}{*}{\multicolumn{2}{|c|}{ Asphalt Mixtures }} & \multicolumn{2}{|c|}{ Indirect Tensile Strength } & \multirow{3}{*}{$\begin{array}{c}\text { ITSR } \\
\mathbf{( \% )}\end{array}$} & \multicolumn{2}{|c|}{ Density $\left(\mathrm{kg} / \mathrm{m}^{3}\right)$} & \multirow{3}{*}{$\left.\begin{array}{c}\text { Va } \\
(\mathbf{\%})\end{array}\right)$} \\
\hline & & \multirow{2}{*}{$\frac{\text { ITS }_{\mathbf{d}}(\mathbf{k P a})}{2631}$} & \multirow{2}{*}{$\frac{\text { ITS }_{\mathbf{w}}(\mathbf{k P a})}{2535}$} & & \multirow{2}{*}{$\begin{array}{l}\text { MD } \\
2907\end{array}$} & \multirow{2}{*}{$\begin{array}{l}\text { Bulk } \\
2681\end{array}$} & \\
\hline & $75 \%$ SSA & & & & & & \\
\hline AC 14surt & $100 \%$ NA & 3218 & 2471 & 77 & 2449 & 2355 & 3.8 \\
\hline $\mathrm{AC}$ & $75 \%$ SSA & 2809 & 2064 & 74 & 2913 & 2770 & 4.9 \\
\hline 20bin/base & $100 \%$ NA & 3074 & 1974 & 64 & 2452 & 2385 & 2.7 \\
\hline
\end{tabular}

The excellent performance of the mixtures with SSA verified in the preliminary study was confirmed in this phase, which means that the developed asphalt mixtures with $75 \%$ SSA guarantee good durability even in the most adverse atmospheric conditions.

The mixtures with SSA performed better than the equivalent mixtures produced only with natural aggregates. The performance of the AC 20 mixture with SSA was inferior to that of the surface course mixture (AC 14), but still higher than the $70 \%$ limit already mentioned. This result is mitigated because AC 20 is less exposed to atmospheric agents.

Moreover, higher air void content values were obtained in the mixtures with SSA, mainly due to the highly rough surface of the SSA, which reduces the workability of the mix. In this regard, the AC 14 mixture with SSA stands out, with a porosity of $7.8 \%$ (above the specifications limit). This high porosity resulted in a slight reduction in dry tensile strength $\left(\mathrm{ITS}_{\mathrm{d}}\right)$ values. However, the increased air void contents of the asphalt mixtures with SSA did not reduce their water sensitivity test results (ITSR), confirming the excellent affinity between SSA and bitumen.

\subsubsection{Resistance to Permanent Deformation of the Selected Asphalt Mixtures}

The wheel tracking test (WTT) was then carried out to characterize the resistance to permanent deformation of the two mixtures with $75 \%$ SSA and the equivalent conventional mixtures. The evolution of the average rut depth of the two slabs of each asphalt mixture can be observed in Figure 8, while the results of the permanent deformation parameters obtained from this test are presented in Table 12.

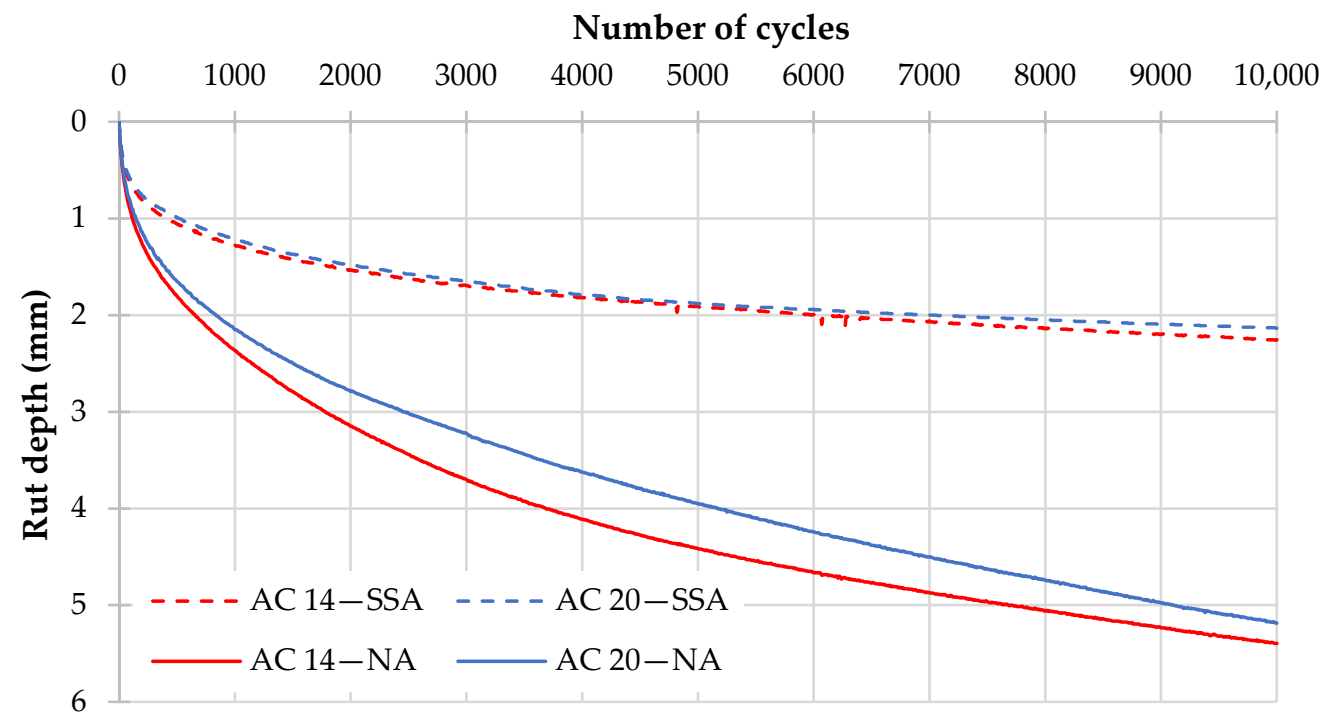

Figure 8. Evolution of the rut depth of the different asphalt mixtures in the WTT test. 
Table 12. Permanent deformation results for mixtures with $75 \%$ SSA and natural aggregates.

\begin{tabular}{|c|c|c|c|c|}
\hline \multicolumn{2}{|l|}{ Asphalt Mixtures } & \multirow{2}{*}{$\begin{array}{c}\begin{array}{c}\text { WTS } \\
\text { AIR }\end{array}_{\text {(mm/10 }} \text { Cycles) } \\
0.07\end{array}$} & \multirow{2}{*}{$\begin{array}{c}\begin{array}{c}\text { PRD }_{\text {AIR }} \\
(\%)\end{array} \\
0.76\end{array}$} & \multirow{2}{*}{$\begin{array}{c}\begin{array}{c}\mathrm{RD}_{\text {AIR }} \\
(\mathbf{m m})\end{array} \\
2.26\end{array}$} \\
\hline 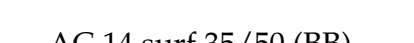 & $75 \%$ SSA & & & \\
\hline AC 14 surr $30 / 50$ (DD) & $100 \%$ NA & 0.20 & 1.80 & 5.40 \\
\hline \multirow{2}{*}{ AC 20 bin/base 35/50 (MB) } & $75 \%$ SSA & 0.05 & 0.71 & 2.13 \\
\hline & $100 \%$ NA & 0.24 & 1.73 & 5.20 \\
\hline
\end{tabular}

The results obtained demonstrate that the mixtures with SSA are much less susceptible to deformation than the equivalent conventional mixtures. Both asphalt mixtures with SSA have wheel tracking slopes $\left(\mathrm{WTS}_{\mathrm{AIR}}\right)$ lower than $0.1 \mathrm{~mm} / 10^{3}$ cycles, less than half of the identical asphalt mixtures with NA. The irregular and rough shape of the SSA may have contributed to this excellent performance at higher temperatures. Figure 9 shows images of the rut depth obtained in the AC 14 mixtures to exemplify the differences between the studied asphalt mixtures (100\% natural aggregates and $75 \%$ SSA).

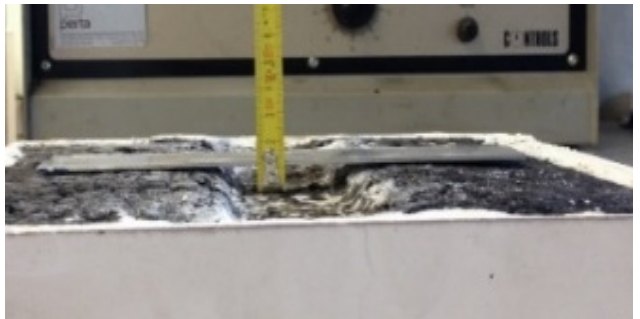

(a)

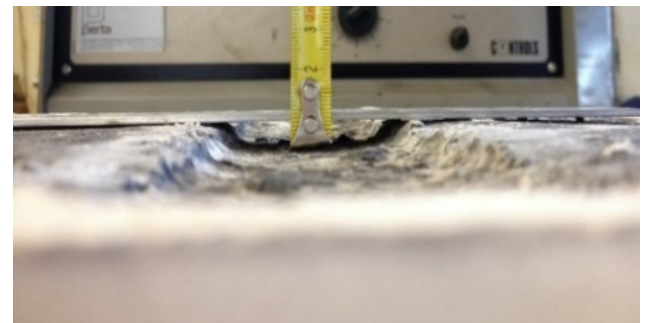

(b)

Figure 9. Rut depths of AC 14 mixtures after the WTT test: (a) natural aggregates; (b) SSA.

\section{Conclusions}

This work aims to develop more sustainable asphalt mixtures that fit within the circular economy objectives. Thus, it was designed to maximize steel slag aggregates (SSA) incorporation in asphalt mixtures. The following conclusions were drawn from this study:

- The SSA characterization revealed the potential of this byproduct for incorporation in asphalt mixtures due to the excellent wearing and polishing resistance and good affinity with bitumen;

- The incorporation of SSA in asphalt mixtures should be limited to $75 \%$ for both the surface (AC 14) and the binder/base (AC 20) courses due to workability problems caused by the SSA roughness and porosity;

- Compared to natural granite aggregates, the high particle density of SSA has a significant impact on the design of asphalt mixtures with SSA. The effective binder content used in asphalt mixtures with 75\% SSA should be reduced from an equivalent value of $5.0 \%$ to only $4.3 \%$ due to the density differential;

- The asphalt mixtures with 75\% SSA still present lower workability, making it challenging to obtain the mixtures' air void content within the specified limits;

- The mechanical performance (water sensitivity and rutting resistance) of the asphalt mixtures with 75\% SSA was excellent, surpassing that obtained for conventional asphalt mixtures with identical compositions produced with natural aggregates.

Summing up, it was concluded that the developed asphalt mixtures with $75 \%$ SSA are sustainable solutions meeting the circularity and performance needs of the paving industry. However, the composition of these mixtures with SSA should be further studied before carrying out a trial pavement section to assess the in situ performance. 


\begin{abstract}
Author Contributions: Conceptualization, C.M., L.N., C.L., M.R., J.O. and H.S.; methodology, L.N., M.R., J.O. and H.S.; validation, J.O. and H.S.; formal analysis, C.M., L.N. and C.L.; investigation, C.M., L.N. and C.L.; resources, M.R.; writing-original draft preparation, C.M., L.N. and C.L.; writingreview and editing, M.R., J.O. and H.S.; visualization, J.O. and H.S.; supervision, J.O. and H.S.; project administration, M.R. and H.S.; funding acquisition, M.R., J.O. and H.S. All authors have read and agreed to the published version of the manuscript.
\end{abstract}

Funding: This research was funded by the PORTUGAL 2020 Partnership Agreement through the Competitiveness and Internationalization Operational Program (POCI) and the European Regional Development Fund (ERDF), under the R\&D Project "RENEw-Construction waste for a circular economy", with reference POCI-01-0247-FEDER-033834.

Institutional Review Board Statement: Not applicable.

Informed Consent Statement: Not applicable.

Data Availability Statement: The presented data are available in the article.

Acknowledgments: The authors would like to thank the technicians from all the institutions involved in this work, who contributed to achieving this study's objectives, and the DST group for providing the materials used in the laboratory work.

Conflicts of Interest: The authors declare no conflict of interest. The funders had no role in the design of the study; in the collection, analyses, or interpretation of data; in the writing of the manuscript, or in the decision to publish the results.

\title{
References
}

1. Morseletto, P. Targets for a circular economy. Resour. Conserv. Recycl. 2020, 153, 104553. [CrossRef]

2. Gardetti, M.A. Introduction and the concept of circular economy. In Circular Economy in Textiles and Apparel; Muthu, S.S., Ed.; Woodhead Publishing: Soston, UK, 2019; pp. 1-11.

3. Mantalovas, K.; Di Mino, G. Integrating Circularity in the Sustainability Assessment of Asphalt Mixtures. Sustainability 2020, 12, 594. [CrossRef]

4. Mantalovas, K.; Di Mino, G.; Jimenez Del Barco Carrion, A.; Keijzer, E.; Kalman, B.; Parry, T.; Lo Presti, D. European National Road Authorities and Circular Economy: An Insight into Their Approaches. Sustainability 2020, 12, 7160. [CrossRef]

5. Mantalovas, K.; Di Mino, G. The Sustainability of Reclaimed Asphalt as a Resource for Road Pavement Management through a Circular Economic Model. Sustainability 2019, 11, 2234. [CrossRef]

6. Plati, C. Sustainability factors in pavement materials, design, and preservation strategies: A literature review. Constr. Build. Mater. 2019, 211, 539-555. [CrossRef]

7. Woszuk, A.; Bandura, L.; Franus, W. Fly ash as low cost and environmentally friendly filler and its effect on the properties of mix asphalt. J. Clean. Prod. 2019, 235, 493-502. [CrossRef]

8. Alnadish, A.M.; Aman, M.Y.; Katman, H.Y.B.; Ibrahim, M.R. Characteristics of Warm Mix Asphalt Incorporating Coarse Steel Slag Aggregates. Appl. Sci. 2021, 11, 3708. [CrossRef]

9. Oluwasola, E.A.; Hainin, M.R.; Aziz, M.M.A. Evaluation of asphalt mixtures incorporating electric arc furnace steel slag and copper mine tailings for road construction. Transp. Geotech. 2015, 2, 47-55. [CrossRef]

10. Choudhary, J.; Kumar, B.; Gupta, A. Utilization of solid waste materials as alternative fillers in asphalt mixes: A review. Constr. Build. Mater. 2020, 234, 117271. [CrossRef]

11. Ferreira, V.J.; Sáez-De-Guinoa Vilaplana, A.; García-Armingol, T.; Aranda-Usón, A.; Lausín-González, C.; López-Sabirón, A.M.; Ferreira, G. Evaluation of the steel slag incorporation as coarse aggregate for road construction: Technical requirements and environmental impact assessment. J. Clean. Prod. 2016, 130, 175-186. [CrossRef]

12. Mladenovič, A.; Turk, J.; Kovač, J.; Mauko, A.; Cotič, Z. Environmental evaluation of two scenarios for the selection of materials for asphalt wearing courses. J. Clean. Prod. 2015, 87, 683-691. [CrossRef]

13. Abd Alhay, B.A.; Jassim, A.K. Steel Slag Waste Applied to Modify Road Pavement; Obaid, A.J., Al-Rafaei, M., Hasson, H.S., Hussain, L.A.A., Hamad, B.H., Ahmed, H.A., Eds.; IOP Publishing Ltd.: Bristol, UK, 2020.

14. Masoudi, S.; Abtahi, S.M.; Goli, A. Evaluation of electric arc furnace steel slag coarse aggregate in warm mix asphalt subjected to long-term aging. Constr. Build. Mater. 2017, 135, 260-266. [CrossRef]

15. Revilla-Cuesta, V.; Ortega-López, V.; Skaf, M.; Pasquini, E.; Pasetto, M. Preliminary Validation of Steel Slag-Aggregate Concrete for Rigid Pavements: A Full-Scale Study. Infrastructures 2021, 6, 64. [CrossRef]

16. Ferreira, S.R. Environmental and Mechanical Behaviour of Granular Materials. Application to National Steel Slags. Ph.D. Thesis, University of Minho, Guimarães, Portugal, 2010. (In Portuguese)

17. Yildirim, I.Z.; Prezzi, M. Chemical, mineralogical, and morphological properties of steel slag. Adv. Civ. Eng. 2011, $2011,463638$. [CrossRef] 
18. Skaf, M.; Manso, J.M.; Aragón, Á.; Fuente-Alonso, J.A.; Ortega-López, V. EAF slag in asphalt mixes: A brief review of its possible re-use. Resour. Conserv. Recycl. 2017, 120, 176-185. [CrossRef]

19. Rodríguez-Fernández, I.; Lastra-González, P.; Indacoechea-Vega, I.; Castro-Fresno, D. Technical feasibility for the replacement of high rates of natural aggregates in asphalt mixtures. Int. J. Pavement Eng. 2021, 22, 940-949. [CrossRef]

20. Ziaee, S.A.; Behnia, K. Evaluating the effect of electric arc furnace steel slag on dynamic and static mechanical behavior of warm mix asphalt mixtures. J. Clean. Prod. 2020, 274, 123092. [CrossRef]

21. Pasetto, M.; Baldo, N. Mix design and performance analysis of asphalt concretes with electric arc furnace slag. Constr. Build. Mater. 2011, 25, 3458-3468. [CrossRef]

22. Maharaj, C.; White, D.; Maharaj, R.; Morin, C. Re-use of steel slag as an aggregate to asphaltic road pavement surface. Cogent Eng. 2017, 4, 1416889. [CrossRef]

23. Hainin, M.R.; Aziz, M.M.A.; Ali, Z.; Jaya, R.P.; El-Sergany, M.M.; Yaacob, H. Steel slag as a road construction material. J. Teknol. 2015, 73, 33-38. [CrossRef]

24. Sorlini, S.; Sanzeni, A.; Rondi, L. Reuse of steel slag in bituminous paving mixtures. J. Hazard. Mater. 2012, 209, 84-91. [CrossRef] [PubMed]

25. Yi, H.; Xu, G.; Cheng, H.; Wang, J.; Wan, Y.; Chen, H. An overview of utilization of steel slag. Procedia Environ. Sci. 2012, 16, 791-801. [CrossRef]

26. Estradas de Portugal. Portuguese Pavement Materials Specifications (in Portuguese-Caderno de Encargos Tipo Obra, 14.03-Pavimentação Características dos Materiais); Estradas de Portugal: Almada, Portugal, 2014.

27. Chomicz-Kowalska, A.; Gardziejczyk, W.; Iwański, M.M. Moisture resistance and compactibility of asphalt concrete produced in half-warm mix asphalt technology with foamed bitumen. Constr. Build. Mater. 2016, 126, 108-118. [CrossRef]

28. Andrade, R.M.A. Laboratory Characterization of Asphalt Mixtures Incorporating Steel Slag Aggregates for Construction. Master's Thesis, Instituto Superior de Engenharia de Lisboa, Lisbon, Portugal, 2015. (In Portuguese).

29. Roque, A.J.; Correia, A.G.; Fortunato, E.; Pardo de Santayana, F.; Castro, F.; Ferreira, S.R.; Trigo, L. Geotechnics in the recovery of recycled steel slag aggregates: A national project. In Conference "Encontro Nacional do Saneamento Básico"; Elsevier: Cascais, Portugal, 2006. (In Portuguese)

30. Paliukaitė, M.; Vorobjovas, V.; Bulevičius, M.; Andrejevas, V. Evaluation of Different Test Methods for Bitumen Adhesion Properties. Transp. Res. Procedia 2016, 14, 724-731. [CrossRef]

31. Blazejowski, K.; Olszacki, J.; Peciakowski, H.; Wójcik-Wiśniewska, M. Testing of bitumen-aggregate affinity by various methods. In Proceedings of the 6th Eurasphalt \& Eurobitume Congress, Prague, Czech Republic, 1-3 June 2016. 